\title{
COMUNICAÇÃo
}

\section{O desafio da inclusão digital}

\author{
The chal lenge of digital inclusion
}

Isa Maria FREIRE ${ }^{1}$

R E S U M O

A B S T R A C T

Apresenta resultados preliminares da pesquisa da autora sobre o desafio que se coloca à sociedade brasileira, com relação à disseminação e utilização das tecnologias digitais de comunicação da informação. Discute as reais possibilidades de atuação democrática através da Internet, bem como a constatação de uma 'brecha digital' entre países ricos e países pobres em informação, em nível internacional, e entre grupos sociais, em nível nacional. Comenta a responsabilidade social dos profissionais da informação, qual seja, a de facilitar a comunicação do conhecimento para aqueles que dele necessitam na sociedade, contribuindo para democratizar o uso dos recursos de informação.

Palavras-chave: inclusão digital; sociedade da informação; responsabilidade social.

This paper presents the preliminary results of the author's research on the challenges the Brazilian society faces, regarding the dissemination and use of the digital technologies of information communication. It discusses the real possibilities of democratic action through the Internet, as well as the 'digital gap' between information rich and information poor countries at the international level, and between social groups, at the national levels. The social responsibilities of

\footnotetext{
${ }^{1}$ Professora e Pesquisadora do Programa de Pós-Graduação em Ciência da Informação, Convênio Ministério da Ciência e Tecnologia, Instituto Brasileiro de Informação em Ciência e Tecnologia, Universidade Federal Fluminense. Rua Lauro Mill ler, 455, $5^{\circ}$ andar, 22290-160, Rio de Janeiro, RJ, Brasil. E-mail: <isalibict.br>. Recebido em 22/2/2004 e aceito para publicação em 9/8/2004.
} 
the information professionals encompassing that of facilitators of knowledge communication to those who need it is thereby stressed, with aims to the democratization of the use of society's information resources.

Key words: digital inclusion, information society, social responsibility.

\section{N T R O D U Ç $\tilde{A} O$}

Nesta comunicação, apresentamos notas de trabalho no processo de reflexão sobre ações para inclusão digital que desenvolvemos na linha de pesquisa: Configurações Sociais e Políticas da Informação, do Programa de Pós-Graduação em Ciência da Informação - Convênio Ministério da Ciência e Informação, Instituto Brasileiro de Informação em Ciência e Tecnologia, Universidade Federal Fluminense (MCT/IBICT-UFF). Destas notas constam, principalmente, um quadro de referência e a perspectiva teórica que orientam nossa abordagem, bem como nossa visão do papel dos profissionais da informação frente ao desafio social e tecnológico criado pela "brecha digital". Atualmente, trabalhamos na proposição de um modelo participativo que possa ser aplicado em ações de inclusão digital em comunidades, e oportunamente comunicaremos os avanços na pesquisa.

Em janeiro de 2003, a Revista Inteligência Empresarial abordou o problema da inclusão digital com uma mensagem de alerta: "a distância entre os providos e os desprovidos digitais está se alargando", entre e intra países. Essa distância, chamada "brecha digital", resulta da "distribuição desigual dos recursos associados às tecnologias da informação e da comunicação" (SORJ, 2003, p.13). E embora essas tecnologias não representem uma solução mágica para o complexo problema da desigualdade, sem dúvida "constituem [atualmente] uma das condições fundamentais da integração na vida social". Nesse sentido, as ações de inclusão digital devem ser consideradas relevantes no conjunto de políticas públicas de inclusão social.

As ações para inclusão digital tornaramse especialmente relevantes depois que a Pesquisa Nacional por Amostra de Domicílios (PNAD) - de 2001 foi a campo, verificando que $12,5 \%$ da população brasileira dispunha de acesso a computador em suas casas, mas os domicílios com altos percentuais de acesso digital estavam localizados, em sua maioria, no Sudeste urbano, principalmente na Região Metropolitana de São Paulo (NERI et al., 2003). Com relação à Internet, segundo o lbope e Ratings (RONDELLI, 2003b), o número de usuários domiciliares no Brasil cresceu 0,7\% em janeiro de 2003, atingindo 7,5 milhões de pessoas, aumentando também o número de horas navegadas em 7,5\% em relação a dezembro de 2002. Contudo, a presença na Web brasileira esteve concentrada nos sites de 'Carreira e Emprego', visitados por 1,4 milhão de internautas, 18,8\% do total de usuários ativos e 'Notícias e Informações', visitados por 3,2 milhões de internautas. Para Rondelli, “... estes são indicadores de que a Internet no Brasil vai se firmando cada vez mais como um importante canal de serviços e mídia para os integrantes das classes A e B ...".

Nesse processo, a diferenciação entre os que têm e os que não têm Internet acrescenta uma nova forma de desigualdade e exclusão social às já existentes, a "exclusão digital".

Néri et al. (2003) relacionaram políticas de inclusão digital e lei de Moore ${ }^{2}$, com o objetivo de "subsidiar o entendimento de campanhas de

\footnotetext{
${ }^{2}$ Segundo essa lei, nos últimos 30 anos a unidade de potência dos computadores tem dobrado a cada 18 -meses. Nesse cenário, a alta obsolescência tecnológica dos computadores levaria à possibilidade de doação de equipamentos computacionais em bom estado a grupos sociais economicamente carentes (NÉRI et al., 2003, p.4) .
} 
doação de computadores", definidas como ações que "buscam difundir o sucesso obtido pela tecnologia de ponta" em grupos economicamente desfavorecidos, partindo da premissa de que o "analfabetismo digital, ao afetar a capacidade de aprendizado, a conectividade e a disseminação de informações, gera conseqüências virtualmente em todos os campos da vida do indivíduo" (NÉRI et al., 2003, p.5). Para Rondelli (2003b) entretanto, a alfabetização digital é apenas uma parte do processo de inclusão digital, "a aprendizagem necessária ao indivíduo para circular e interagir no mundo das mídias digitais como consumidor e como produtor de seus conteúdos e processos".

Também para Lazarte (2000, p.51) os elementos necessários para inclusão não devem contemplar apenas o acesso físico à infraestrutura e a conexão em rede e computadores, mas, especialmente, a capacitação das pessoas para utilizar estes meios de comunicação da informação e, principalmente, para criar a "possibilidade de uma incorporação ativa no processo todo de produção, compartilhamento e criação cultural", os chamados "conteúdos". Nesse sentido,

A forma de se proporcionar este acesso deve estar integrada às condições locais existentes, em termos de suas organizações, tanto quanto em seus referenciais culturais. Centros de produção, criação e compartilhamento cultural (e de acesso à rede) devem estar integrados a associações comunitárias, centros religiosos, igrejas etc. (LAZARTE, 2000, p.48).

Nos "quatro passos para inclusão digital" que propõe, Rondelli coloca que "a oferta de computadores conectados em rede é o primeiro..., mas não é o suficiente para se realizar a pretensa inclusão digital" (RONDELLI, 2003a). O segundo passo é o de "criar oportunidades para que os aprendizados feitos a partir dos suportes técnicos digitais possam ser empregados no cotidiano da vida e do trabalho", mas para que isso aconteça o terceiro passo tem que vir junto: o entorno institucional. Nesse sentido, "é preciso muito investimento financeiro, pois essa tecnologia não é gratuita, mesmo que pública. E tal desenho institucional não se faz de modo aleatório". Para a autora, o quarto passo consiste em

(...) entender que inclusão digital pressupõe outras formas de produção e circulação da informação e do saber diferentes destas mais tradicionais que nos acostumamos a freqüentar. Portanto, há também um elemento importante de inovação no uso das tecnologias (RONDELLI, 2003a).

Pois, na medida em que permitem que se estabeleçam relações "descentralizadas e verticalizadas" entre produtores e consumidores de informação e conhecimento, as mídias digitais possibilitam que ambos possam permutar suas funções e papéis sociais, ora como produtores, ora como consumidores dos processos e conteúdos que circulam na mídia digital. Por isso mesmo, "processos de inclusão só ocorrem se a ampliação do acesso à qualquer uma das mídias existentes for acompanhada da inserção dos indivíduos em um universo cultural e intelectual mais rico que os motivem a utilizá-las. ..." (RONDELLI, 2003a).

É nesse quadro que, segundo Assmann (2000), "as políticas públicas podem fazer a diferença", de modo a favorecer o crescimento de uma sociedade da informação onde todos tenham "acesso a uma quota parte mínima dos novos serviços e aplicações" das tecnologias digitais de informação e comunicação. Isto torna-se necessário porque

As novas tecnologias da informação e da comunicação já não são meros instrumentos no sentido técnico tradicional, mas feixes de propriedades ativas. São algo tecnologicamente novo e diferente. As tecnologias tradicionais serviam como instrumentos para aumentar o alcance dos 
sentidos (braço, visão, movimento, etc.). As novas tecnologias ampliam o potencial cognitivo do ser humano (seu cérebro/mente) e possibilitam mixagens cognitivas complexas e cooperativas (ASSMANN, 2000, p.15).

Nesse contexto, uma "parceria cognitiva" se estabelece entre o ser humano e as máquinas inteligentes, de modo que termos como "usuário" não mais expressariam essa relação cooperativa adequadamente, uma vez que o papel das tecnologias de informação e comunicação

(...) já não se limita à simples configuração e formatação, ou, se quiserem, ao enquadramento de conjuntos complexos de informação. Elas participam ativamente do passo da informação para o conhecimento. Está acontecendo um ingresso ativo do fenômeno técnico na construção cognitiva da realidade. Doravante, nossas formas de saber terão um ingrediente [...] derivado da nossa parceria cognitiva com as máquinas que possibilitam modos de conhecer anteriormente inexistentes. Em resumo, as novas tecnologias têm um papel ativo e coestruturante das formas do aprender e do conhecer. Há nisso, por um lado, uma incrível multiplicação de chances cognitivas, que convém não desperdiçar, mas aproveitar ao máximo (ASSMANN, 2000, p.11).

Por isso mesmo, a democratização do acesso às tecnologias digitais de informação e comunicação deveria ser vista como elemento fundamental nas políticas de inclusão social. Nesse sentido, Assmann (2000) insiste na necessidade de formulação de políticas públicas que possam ajudar as populações economicamente carentes a se beneficiarem das vantagens do progresso tecnológico, promovendo "o acesso universal à info-alfabetização e à info-competência" de modo a reforçar o caráter democrático da sociedade da informação (ASSMANN, 2000, p.6). Entretanto, embora este seja um problema socialmente significativo, Néri et al. assinalam que

Existem poucos diagnósticos e debates no contexto brasileiro sobre o binômio inclusão/exclusão digital. [...] A discussão raramente envereda pelo acesso às tecnologias pelo lado do [...] usuário pobre [...] É preciso desenvolver tecnologias para o uso da tecnologia da informação no combate à pobreza e à desigualdade (NÉRI et al., 2003, p.5).

Nesse sentido, trazemos como fundamento para esta breve reflexão as colocações de Araújo (2001) sobre o problema, quando destaca que,

o verdadeiro desafio [é o de] criar tecnologias, construir ferramentas [intelectuais] e sistemas mais eficazes, não só para gerenciar informação, mas também para facilitar ao ser humano a transformação da informação em conhecimento e, conseqüentemente, em ação na sociedade (ARAUJO, 2001, p.11-12).

\section{Na trilha do futuro}

A pista do caminho a seguir é proposta por Castells, para quem a questão da inclusão digital vai além do desenvolvimento tecnológico:

A questão crítica é mudar [...] para o aprendizado-de-aprender, uma vez que a maior parte da informação [estará] on-line e o que realmente [será] necessário é a habilidade para decidir o que procurar, como obter isso, como processá-lo e como usá-lo para a tarefa específica que provocou a busca de informação. Em outras palavras, o novo aprendizado é orientado para o desenvolvimento da capacidade educacional de transformar informação e conhecimento em ação (Dutton, 1999) (CASTELLS, 2003, p.103). 
Todavia, ele alerta que ainda que não saibamos o bastante sobre as dimensões sociais e econômicas da Internet, sabemos [que] a melhoria de nossa condição dependerá do que as pessoas fizerem, inclusive você e eu (CASTELLS, p.107). ${ }^{3}$

Em nossa visão, depende não somente de nossa ação no mundo mas, especialmente, da nossa conscientização sobre o poder transformador da informação. ${ }^{4} \mathrm{E}$ aqui se revela um pressuposto na nossa abordagem: a responsabilidade social dos profissionais da informação na sociedade contemporânea, no que diz respeito muito mais à visão de mundo do que propriamente à competência no uso das tecnologias digitais e intelectuais. ${ }^{5}$

Nesse sentido, a questão remeteria à aposta de Pascal retomada por Goldmann (1979):

A aposta é fundamentalmente a expressão do paradoxo do homem e sua condição. Para que o homem viva como homem, ele deve engajar sua vida sem reservas, na esperança de um valor autêntico cujo sinal mais claro é que ela é realidade. É o paradoxo fundamental da condição humana: a união dos contrários, a união do espírito e da matéria, [...] porque essa realidade dupla é encarnação. ... [Em Georg Lukàcs] reaparece essa idéia de que ser homem significa engajar sem reservas sua existência na afirmação eternamente improvável de uma relação possível entre o dado sensível e o sentido, entre Deus e a realidade empírica atrás da qual ele se esconde, relação [...] que não se pode demonstrar e na qual, entretanto, é necessário engajar toda sua existência (GOLDMANN, 1979, p.53).

Ele aposta, pois, na capacidade dos indivíduos construírem uma verdadeira comunidade humana no futuro, fundamentando nossa reflexão sobre o papel dos profissionais que atuam no campo da informação: contribuir, de um lado, para ampliar a teia mundial de comunicação da informação e, de outro, para diminuir a "info-exclusão", aumentando as possibilidades de livre acesso aos estoques de informação. Pois, segundo Quéau, a partir do século XXI:

O acesso à informação torna-se um fator-chave na luta contra a pobreza, a ignorância e a exclusão social. Por essa razão não se pode deixar apenas nas mãos das forças do mercado o cuidado de regular o acesso aos conteúdos das "autovias da informação". Pois são esses conteúdos que vão tornar-se o desafio fundamental do desenvolvimento humano nos âmbitos da sociedade da informação. O ciberespaço deve permitir a todos o acesso às informações e aos conhecimentos necessários para a educação e para o desenvolvimento de todos os homens (QUÉAU, 2001, p.179).

Enfim, encerrando estas breves reflexões, parece-nos que no caso da inclusão digital não há um manual de procedimentos a ser consultado, nem tampouco um mapa do caminho a seguir. O que, certamente, representa uma oportunidade histórica para cientistas e profissionais da informação trabalharem no sentido de pensar e desenvolver modos e meios para inclusão digital de populações social e

\footnotetext{
${ }^{3}$ Tambémpara Quéau (2001), "amelhor direção éo 'atro'. [...]E aquele que émais desfavoreciob é ainola mais 'autro', exatamente porque ele é o mais desfavorecido [é o] que melhor representa o bem comum".

4 "[Pois] se a informação é a mais poderosa força de transformação do homem [o] poder da informação, al iado aos modemos meios de comunicação de massa, tem capacidade il imitada de transformar allturalmente o homem, a sociedade e a própria humanidade como um todo" (ARAUJO, 1994. p.84).

${ }^{5}$ Segundo Lévy (2001, p.6), "O papel da infomática e das técnicas de commicação com base digital [é] promover a construção dos coletivos inteligentes, nos quais as potencialidades sociais e cognitivas de cada umpoderão desenvolver-se e ampliar-se demaneira recíproca. Dessa perspect iva, oprincipal projeto arquitetônico db séaulo XXI será imaginar, constnuir e organizar o espaço interativo e móvel ab ciberespaço $[\ldots]^{\prime \prime}$.
} 
economicamente carentes, pari passu com ações pela cidadania e inclusão social.

Esta seria, a nosso ver, a parte que nos cabe na tarefa coletiva de construir uma "socieda- de em rede" democrática e justa: transportar, nas asas da informação, ${ }^{6}$ o conhecimento para todos aqueles que dele necessitem, no processo social (e vital) de transformar sonhos em realidade.

\section{R E F E R E N C I A S}

ARAUJO, V.M.R.H. Miséria informacional. O paradoxo da subinformação e superinformação. Revista Inteligência Empresarial, Rio de Janeiro, n.7, p.11-12, 2001.

ARAUJO, V.M.R.H. Sistemas de recuperação da informação: nova abordagem teórico-conceitual. 1994. Tese (Doutorado em Comunicação e Cultura) - Escola de Comunicação da Universidade Federal do Rio de Janeiro, Rio de Janeiro, 1994.

ARAUJO, V.M.R.H.; FREIRE, I.M. Conhecimento para o desenvolvimento: reflexões para o profissional da informação. Informação \& Sociedade: Estudos, João Pessoa, v.9, n.1, p.61-75, 1999.

ASSMANN, H. A metamorfose do aprender na sociedade da informação. Ciência da Informação, Brasília, v.29, n.2, p.7-15, 2000.

CASTELLS, M. A galáxia da Internet: reflexões sobre a Internet, os negócios e a sociedade. Rio de Janeiro: Jorge Zahar, 2003. p.103-107.

DUTTON, W.H. Society on the Line: Information Politics in the Digital Age. New York: Oxford Press University, 1999.

FARRADANE, J. Knowledge, information and information science. Journal of Information Science, v.2, 1980.

FREIRE, I.M. A responsabilidade social da Ciência da Informação e/ou O olhar da consciência possível sobre o campo científico. 2001. Tese (Doutorado em Ciência da Informação) - Instituto Brasileiro de Informação em Ciência e Tecnologia, Universidade Federal do Rio de Janeiro, Rio de Janeiro, 2001.
GOLDMANN, L. Dialética e cultura. Rio de Janeiro: Paz e Terra, 1979. p.53.

LAZARTE, L. Ecologia cognitiva na sociedade da informação. Ciência da Informação, Brasília, v.29, n.2, p.43-51, 2000.

LÉVY, P. A inteligência coletiva: por uma antropologia do ciberespaço. 3.ed. São Paulo: Loyola, 2000.

LÉVY, P. As tecnologias da inteligência: o futuro do pensamento na era da informática. Rio de Janeiro: Ed. 34, 1993.

NERI, M.; CARVALHAES, L.; NERI, A.L.; PIERONI, A. Lei de Moore e Políticas de Inclusão Digital. Revista Inteligência Empresarial, Rio de Janeiro, n.14, p.4-9, 2003

QUÉAU, P. Cibercultura e info-ética. In: MORIN, E. (Org.). A religação dos saberes: o desafio do século XXI. Rio de Janeiro: Bertrand Brasil, 2001. Jornadas temáticas (Paris, França, 1998).

RONDELLI, E. Quatro passos para a inclusão digital. Disponível em: <www.icoletiva.com.br>. Acesso em: 7/8/2003a.

RONDELLI, E. Mídia, informação e conhecimento. Disponível em <www.icoletiva.com.br>. Acesso em: 7/8/2003b.

SORJ, B.brasil@povo.com: a luta contra a desigualdade na Sociedade da Informação. Rio de Janeiro: Jorge Zahar, 2003. p.13.

\footnotetext{
${ }^{6}$ Uma metáfora que criamos para o conceito de informação como "representação do conhecimento", proposto por Farradane (FARRADANE, 1980).
} 